\title{
Material substitution of coil tubes in CT drilling technology for hard rocks
}

\author{
R. Roufail \& V. Rasouli \\ Deep Exploration Technologies Cooperative Research Centre, and \\ Department of Petroleum Engineering, Curtin University, Australia
}

\begin{abstract}
The fatigue life of coil tubing is known for its low cycle due to multiple bend events. Since fatigue failure is usually catastrophic, the tube is commonly withdrawn from service earlier based on its operation life database. The coil tube in a drilling system needs to be light in weight to facilitate the transportation and manoeuvring of the equipment. It also needs to last for few hundreds of drill holes without failure to speed the drilling process and decrease the cost per drilled hole. The conventional material of the coil tube available in the market is high strength low alloy steel (HSLAS), which is relatively heavy for frequent repositioning, and has a low bending fatigue life.

In this study material selection analysis is performed on a variety of candidate material using performance index method. The performance indices are evaluated based on the candidate materials' unit weight, bend-ability, load carrying capacity, specific stiffness, and fracture toughness and corrosion resistance. The results suggested composite materials, 56\% E-class glass fibre, $73 \%$ E-class glass fibre and $63 \%$ carbon fibre scored the highest performance indices that are 62.2, 51.4 and 48.2, respectively. Such materials are suitable alternatives to the high strength low alloy steel. Candidate material properties are extracted from literature. A further study is in progress for existing coil tubes, where their material properties will be investigated for selection purposes. Keywords: coil tubing, material selection, performance index fatigue, drilling.
\end{abstract}

\section{Introduction}

Coil tubing is mainly used in the oil and gas industry for work-over applications, stimulation purposes, well logging, drilling and other applications [1, 2]. Mineral 
exploration is in a race to employ drilling technology that can perform the drilling process in a short and inexpensive manner. In order to utilise coil tube technology in mineral exploration operations, it requires drilling multiple deep small size boreholes as fast as possible to reach possible ore body. The drilled rock particles, which could be ultrafine size, below $10 \mu \mathrm{m}$, are collected at the surface for various analyses including their mineral content.

One of the advantages of using coil tubing in drilling is that it is a fast process relative to the other conventional drilling processes. The rig up is quick and the coil tubing system is mobile. Therefore, the cost per drill hole would be cheap and the exploration is relatively fast. Therefore, mapping of an ore body is feasible using coil tubing drilling technology. Coil tube strings available in the market have low fatigue life due to the multiple bend and flattening events during operation [3].

Coil tube string that is currently in use is made of high strength low alloy steel. This type of material has been functioning well for oil and gas applications since it has reasonable ductility, high weldability and high corrosion resistance, if not exposed to an extreme acidic or hydrogen sulfide environment. However, experience proved that the HSLA tubing has limitations. For example, its fatigue life is ultra low, less than 100 operational cycles. The weight of the steel tubes is relatively heavy, which hinders manoeuvring and handling. The weight causes possible operation casualties and increases the general cost. Therefore, a lighter coil tube such as composite carbon fibre or fibreglass tubing is being investigated as an option to replace the steel tubes by Jaworsky and Williams [4]. Preliminary samples of carbon fibre tubing are successfully tested for drilling operation by DET CRC training facility at Brukunga $[5,6]$. The carbon fibre tube material used was produced by Teakle Composites, Australia [7].

The material properties and behaviour of the carbon fibre tube needs to be further investigated to confirm that it is competent to the HSLA tubes and to verify that it is the optimum choice for drilling operation for mineral exploration. In this paper the material selection analysis is performed on a variety of candidate material using performance index method to assess possible replacement material for currently used HSLA.

\section{Stresses applied on coil tubing}

During operation the coil tubing is exposed to multiple mechanical stresses, such as tension, compression, creep, fatigue, erosion, as well as, chemical wear due to the corrosive environment, especially in the oil and gas industry applications [2].

The reel applies tension on the tube, via a motor drive system, to maintain the tube position on the rollers and the spool. The coil tubing is exposed to six different bending events during the drilling process, as illustrated in Figure 1. Three bend events occur while transporting the CT into the drill hole. One bend is wrapped around the reel, and then the tube is pulled off the reel by the injector head. The reel resists the pull of the tube, creating tension load that straightens the bent tube. The second bend event occurs around the tubing guide. The tube is then pulled towards the injector head, where the tube is straightened, facing the 
ground to start the drilling process. When the drilling job is finished, similar three bend events take place. The six bend events are considered to be a one event in an industrial cycle, which is equivalent to drilling one hole. If a deviated angled drilling operation takes place that would add two more bend events to the drilling process.

During operation the coil tube is also exposed to internal pressure due to the fluid pumped into the system. The fluid is utilized for the drilling process to drive the downhole motor and to lift the drilled cuttings to the surface. The bent section of the tube is exposed to tri-axial stress, the internal pressure from the fluid, tensile stress and compressive stress at both sides of the tube circumference, as illustrated in Figure 1.

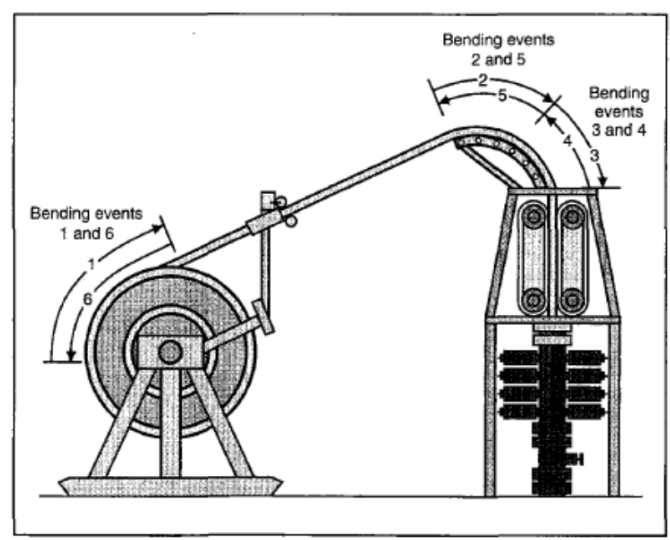

Figure 1: Schematic diagram of the coiled tubing bending events when running in and out of the Wellbore, after Jaworsky and Williams [4].
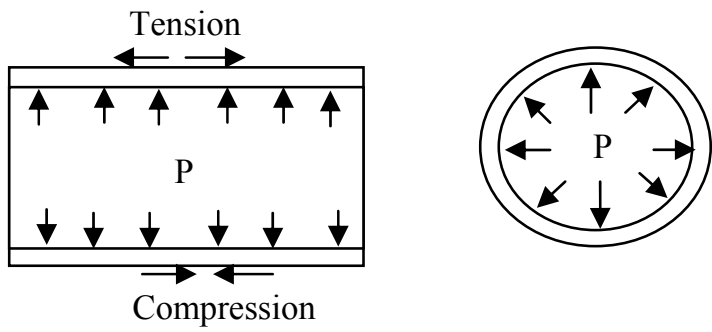

Figure 2: Schematic diagram of stress distribution on coil tubing.

Stresses on the bent section of the tube, along with the internal pressure, exposes the tube to wall thinning and localised plastic deformation. The uneven 
deformation along the tube leads to burst failure. Jaworsky and Williams [4] collected data from field testing and their empirical evaluation showed that when the OD of the tube increases by $3 \%$, the wall thickness decreases by $7.5 \%$, which leads to an increase of burst and collapse pressure rate by about $10 \%$. Jaworsky and Williams [4] added that yield strength of tubing samples, acquired from field services, decreased.

\section{Material selection procedure}

Material selection is based on the requirements of the application and the performance of the work piece. Possible candidate materials that will deliver the requirements are chosen. Selection procedures mainly depend on experience and focus on a specific property that is essential at the time of selection. This process is valid for initial screening when the material property is rigid and cannot be compromised. According to Farag [8], there are other soft properties that are usually ignored during the selection process which can be quantified. If the soft properties are taken into consideration during the selection process, the material selected for the application will most probably be one of the most optimum choices.

Material selection commences by stating the rigid properties that is a must for the material to perform the job required. Rigid properties could be narrowed down to one or two that are comparable such as strength and weight, or ductility and cost. Ashby [9] created materials selection charts of Young's modulus versus density or material strength versus density to address the initial selection procedure. Dargie et al. [10] developed a mathematical model to assist in the initial selection procedure. Initial selection using rigid parameters inevitably leads to multiple possible candidate materials which all will perform the job. However, one of the candidate materials would be a better choice if the soft properties were quantitatively evaluated. Performance index method is a practical quantitative method that can be used to evaluate the soft properties.

The rigid properties in the coil tubing selection process would be ductility and weight. Ductility is needed to bend the tube string around the reel and light weight is essential, since the rig is transportable and the drilling process needs to be fast for productivity. Such properties would exclude high strength brittle material choices such as high carbon steels or thermoset polymers or ceramics. Initial selection is considered an elimination process rather than a selection process. The suggested materials are still wide enough for confusion. Therefore, ranking the soft properties is essential to reach a quantitative and knowledgeable decision.

The selection process is split into three main steps. The first step prioritises the material properties required to perform the job using the digital logic method and weighting factor. The second step evaluates the candidate materials and their properties relative to each other. The third and last step relates the required priorities to the candidate materials' properties as per the flow chart shown in Figure 3. 


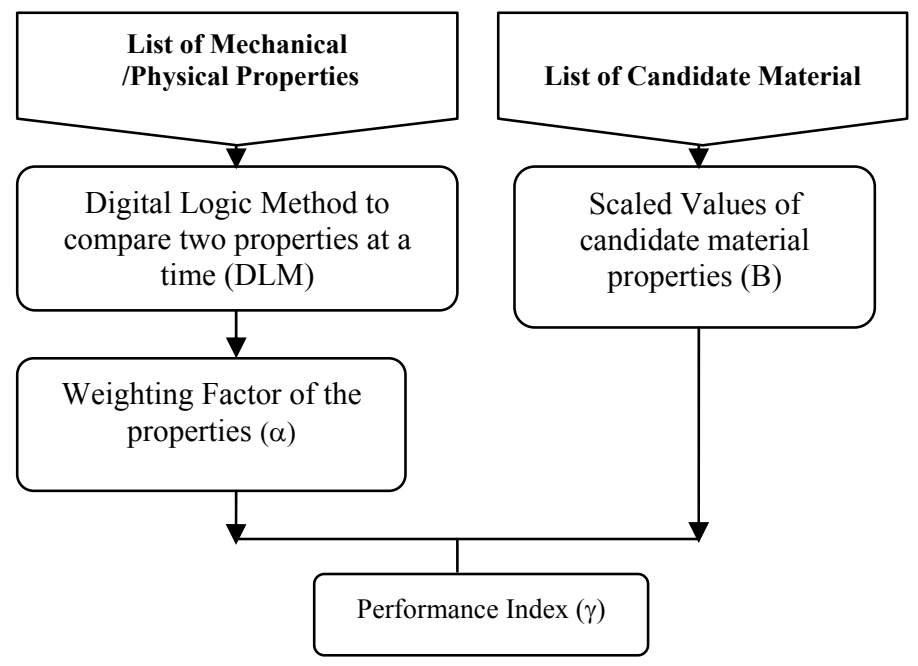

Figure 3: Material selection flow chart.

\subsection{Digital logic method (DLM)}

Digital logic method evaluates two material properties at a time. The two parameters are evaluated based on their importance for the application. The properties are given values of 0 and 1 . The more important parameter is given a 1 and the less important parameter is given a 0 . The total number of decision that will come out of the DLM is according to equation (1) where $\mathrm{N}$ is the number of material properties evaluated.

$$
\text { Number of Decisions }=\frac{N(N-1)}{2}
$$

The selection of the proper properties is crucial for the success of the application.

\subsection{Material properties selection}

The coil tube needs to be bendable, with a relatively high fatigue life, light in weight for transportation, resist buckling during the drilling process, corrosion and wear resistant and inexpensive. The seven parameters listed above could be translated into material properties as follows:

- For bend ability, the material needs to possess a relatively low yield stress and should have a high elastic deformation range so it would fall under the ductile category.

- To decide on the fatigue life, the endurance limit of the material needs to be evaluated.

- The light weight parameter is dictated by the density of the material chosen and the thickness of the tube selected. For the sake of comparison, the tube 
outer diameter and thickness values are fixed to 2 inch outer diameter and wall thickness of 0.175 inch.

- The tube needs to resist buckling during the drilling process. The physical parameter that indicates buckling factor is the modulus of elasticity.

- Corrosion resistance of the material are evaluated on a scale of 5 to 1 , where 5 is excellent, 4 is very good, 3 is good, 2 is poor and 1 is very poor.

- Wear resistant could be tested relative to time and a value of weight loss per unit time can be recorded as the wear rate.

- Cost of the tube is based on the raw material and its fabrication divided by the number of drill holes it can perform before retiring the tube.

All the above parameters will be considered in the study, based on measured values of the material available in hand. However, for the sake of constructing a material selection model, material properties were based on literature and narrowed down to the following parameters:

- Yield stress values for the bend ability

- Tensile stress for loading capacity before failure,

- Modulus of elasticity for buckling,

- Fracture toughness for fatigue resistance that will be replaced by measured endurance limit,

- Density for weight,

- Corrosion resistance.

The above parameters are evaluated relative to their significance for the application. Two parameters at a time are compared using the digital logic method, where the more important parameter earns one and the less important earns a zero. The results of the DLM evaluation are listed in Table 1.

Table 1: $\quad$ Digital logic method evaluation.

\begin{tabular}{|c|c|c|c|c|c|c|c|c|c|c|c|c|c|c|c|c|c|}
\hline & & \multicolumn{16}{|c|}{ Decision Number } \\
\hline Application & Property & 1 & 2 & 3 & 4 & 5 & 6 & 7 & 8 & 9 & 10 & 11 & 12 & 13 & 14 & 15 & Total \\
\hline Bending & $\begin{array}{l}\text { YS-Yield Stress } \\
(\mathrm{MPa})\end{array}$ & 1 & 1 & 1 & 1 & 1 & & & & & & & & & & & 5 \\
\hline Fracture & $\begin{array}{l}\text { TS-Tensile Stress } \\
\text { (MPa) }\end{array}$ & 0 & & & & & 0 & 0 & 0 & 1 & & & & & & & 1 \\
\hline Buckling & $\begin{array}{l}\text { E-Modulus of Elasticity } \\
\text { (GPa) }\end{array}$ & & 0 & & & & 1 & & & & 0 & 0 & 0 & & & & 1 \\
\hline Fatigue & $\begin{array}{l}\mathrm{K}_{\mathrm{IC}} \text {-Fracture Toughness } \\
\left(\mathrm{MPa} \mathrm{m}^{\wedge} 1 / 2\right)\end{array}$ & & & 0 & & & & 1 & & & 1 & & & 1 & 1 & & 4 \\
\hline Weight & $\begin{array}{l}\text { Density } \\
\left(\mathrm{gm} / \mathrm{cm}^{3}\right)\end{array}$ & & & & 0 & & & & 1 & & & 1 & & 0 & & 1 & 3 \\
\hline Corrosion & Corrosion & & & & & 0 & & & & 0 & & & 1 & & 0 & 0 & 1 \\
\hline & Total positive decisions & & & & & & & & & & & & & & & & 15 \\
\hline
\end{tabular}




\subsection{Weighting factor relative emphasis coefficient $(\alpha)$}

The weighting factor is also identified as relative emphasis coefficient $(\alpha)$ (Farag [8]). Weighting factor is calculated by dividing the number of positive decision for each property by the total number of decisions. Results are listed in Table 2. The results showed that yield stress has the highest weighting factor, followed by fracture toughness, then density. The least weighting factors are tensile strength, modulus of elasticity, and corrosion resistance.

Table 2: Weighting factor.

\begin{tabular}{|l|l|c|c|}
\hline \multicolumn{1}{|c|}{ Application } & \multicolumn{1}{|c|}{ Property } & Positive Decision & Weighting Factor $(\alpha)$ \\
\hline Bending & $\begin{array}{l}\text { YS-Yield Stress } \\
(\mathbf{M P a})\end{array}$ & 5 & 0.33 \\
\hline Fracture & $\begin{array}{l}\text { TS-Tensile Stress } \\
(\mathbf{M P a})\end{array}$ & 1 & 0.07 \\
\hline Buckling & $\begin{array}{l}\text { E-Modulus of Elasticity } \\
(\mathbf{G P a})\end{array}$ & 1 & 0.07 \\
\hline Fatigue & $\begin{array}{l}\mathbf{K}_{\mathrm{IC}-\text {-Fracture Toughness }} \\
\left(\mathbf{M P a} \mathbf{m}^{\mathbf{1} / 2}\right)\end{array}$ & 4 & 0.27 \\
\hline Weight & $\begin{array}{l}\text { Density } \\
\left(\mathbf{g m} / \mathbf{c m}^{\mathbf{3}}\right)\end{array}$ & 3 & 0.20 \\
\hline Corrosion resistance & Corrosion & 1 & 0.07 \\
\hline
\end{tabular}

\subsection{Scaling candidate material}

A list of candidate material that satisfies the rigid requirements and their mechanical and physical properties are gathered. The soft parameters for the candidate materials are listed in Table 3. The high strength and low alloy steels, G90 and G100 are conventional coil tube material used in the drill rigs at the oil and gas industry. Three types of composite material, $63 \%$ and $56 \%$ carbon fibre and $73 \%$ glass fibre are chosen for their light weight and high strength properties. The composite material property values are based on fibres that are aligned in the direction of loading, embedded in an epoxy matrix. Aluminium alloy 6061 is also chosen because it is known for its relatively high tensile strength, fatigue strength and high corrosion resistance properties (MacMaster et al. [11]) which makes it compatible to the other four candidate materials.

The properties of the candidate material are scaled (B) based on the best value in the list which is given a 100 . The other materials are scaled proportionally. The best value could be the lowest, according to the function of the property in application. For example, the yield stress and density of the material are required 
Table 3: $\quad$ Properties of candidate material.

\begin{tabular}{|lc|c|c|c|c|c|}
\cline { 2 - 7 } \multicolumn{1}{c|}{} & $\mathbf{1}$ & $\mathbf{2}$ & $\mathbf{3}$ & $\mathbf{4}$ & $\mathbf{5}$ & $\mathbf{6}$ \\
\hline Candidate Mate rial & $\begin{array}{c}* \mathrm{YS} \\
(\mathrm{MPa})\end{array}$ & $\begin{array}{c}\mathrm{TS} \\
(\mathbf{M P a})\end{array}$ & $\begin{array}{c}\mathrm{E} \\
(\mathrm{GPa})\end{array}$ & $\begin{array}{c}\mathrm{K}_{\mathrm{IC}} \\
\left(\mathbf{M P a} \mathrm{m}^{1 / 2}\right)\end{array}$ & $\begin{array}{c}* \text { Density } \\
\left(\mathbf{g m} / \mathrm{cm}^{3}\right)\end{array}$ & Corrosion \\
\hline GT90 & 620 & 668 & 205 & 50 & 7.9 & 3 \\
\hline GT100 & 859 & 928 & 205 & 50 & 7.9 & 3 \\
\hline CF-63\% & 107 & 1725 & 159 & 1.36 & 1.6 & 5 \\
\hline GF-E-class-56\% & 26 & 1028 & 43 & 0.4 & 2.0 & 5 \\
\hline GF-E-class-73\% & 42 & 1642 & 56 & 1 & 2.2 & 5 \\
\hline Aluninum 6061 & 322 & 365 & 69 & 33.3 & 2.7 & 4 \\
\hline
\end{tabular}

Corrosion Resistance Scale: 5: Excellent; 4: V. Good; 3: Good; 2: Fair; 1: Poor.

to be low to tolerate bending and light in weight, respectively. For such parameters, the scaled values are calculated as per equation (3). The tensile strength, modulus of elasticity, fracture toughness values and corrosion resistance, are required to be the highest in the list to allow high strength, buckling resistance, long fatigue life and high corrosion resistance, respectively. The equations used for scaling are as per equations (2) and (3). The scaled values of the candidate materials are listed in Table 4.

$$
\begin{aligned}
& B=\frac{\text { Numerical Value of Property }}{\text { Maximum Value in the List }} * 100 \\
& B=\frac{\text { Minimum Value in the List }}{\text { Numerical Value of Property }} * 100
\end{aligned}
$$

Table 4: $\quad$ Scaled values of properties (B).

\begin{tabular}{|l|c|c|c|c|c|c|}
\cline { 2 - 7 } \multicolumn{1}{c|}{} & 1 & $\mathbf{2}$ & $\mathbf{3}$ & $\mathbf{4}$ & $\mathbf{5}$ & $\mathbf{6}$ \\
\hline Candidate Material & $\begin{array}{c}* \\
(\mathrm{MPa})\end{array}$ & $\begin{array}{c}\mathrm{TS} \\
(\mathrm{MPa})\end{array}$ & $\begin{array}{c}\mathrm{E} \\
(\mathrm{GPa})\end{array}$ & $\begin{array}{c}\mathrm{K}_{\mathrm{IC}} \\
\left(\mathrm{MPa} \mathbf{m}^{1 / 2}\right)\end{array}$ & $\begin{array}{c}* \text { Density } \\
\left(\mathrm{gm}^{3} / \mathrm{cm}^{3}\right)\end{array}$ & Corrosion \\
\hline GT90 & 4 & 39 & 100 & 100 & 20.5 & 60 \\
\hline GT100 & 3 & 54 & 100 & 100 & 20.5 & 60 \\
\hline CF-63\% & 24 & 100 & 77.4 & 2.72 & 100 & 100 \\
\hline GF-E-class-56\% & 100 & 60 & 20.9 & 0.8 & 81.7 & 100 \\
\hline GF-E-class-73\% & 62 & 95 & 27.3 & 2 & 74.2 & 100 \\
\hline Aluninum 6061 & 8 & 21 & 33.7 & 66.6 & 59.6 & 80 \\
\hline
\end{tabular}




\subsection{Performance index}

The scaled values of the candidate materials are related to the required mechanical / physical properties using performance index equation (4).

$$
\gamma=\sum_{i}^{n} B_{i} \alpha_{i}
$$

The sum of the scaled values for each material property is multiplied by its equivalent weighting factor property, producing a one index value for each material. The higher the index value, the higher the performance of the material.

Ranking the material based on their performance index values showed that the highest value, which suggests the best material to select for coil tubing rig is glass fibre composite $56 \%$ and $73 \%$, respectively and the third in line is the carbon fibre composite as in Table 5.

Table 5: $\quad$ Performance index $(\gamma)$.

\begin{tabular}{|l|c|c|}
\hline Candidate Mate rial & $\begin{array}{c}\text { Performance } \\
\text { Index }(\boldsymbol{\gamma})\end{array}$ & Ranking \\
\hline GT90 & 46.4 & 5 \\
\hline GT100 & 47.1 & 4 \\
\hline CF-63\% & 48.2 & 3 \\
\hline GF-E-class-56\% & 62.2 & 1 \\
\hline GF-E-class-73\% & 51.4 & 2 \\
\hline Aluninum 6061 & 42.0 & 6 \\
\hline
\end{tabular}

\section{Conclusions}

Using a technology such coil tubing in a different application such as drilling for mineral exploration, would require a faster outcome for cheaper cost per drill hole. This would allow more drill holes in a short time that can lead to a faster executive decision concerning the initiation of a mine or a go or no go for further mine investigation. The coil tube material needs to be substituted by a lighter and durable tube.

In this study the material selection process is based on candidate materials chosen with their properties listed in literature. The study addressed six properties, yield stress, tensile stress, modulus of elasticity, fracture toughness, density and corrosion resistance, based on the need of a bendable material that can withstand multiple fatigue bending events, resist buckling during operation, light in weight and resists corrosion. Six suggested candidate materials are studied. Two of them are already in use in the coil tube technology, which are two types of high strength low alloy steels, composite materials that are carbon and glass fibres and aluminium alloy 6061. The best material scored the highest performance index is the $56 \%$ glass fibre alloy.

For the sake of a convenient material selection of tubes for the coil tube rig that will be used for hard rock drilling for mineral exploration, available coil 
tube materials and their properties need be tested. The most important parameter, which causes most of the catastrophic failures, is the endurance limit for fatigue bend loading. The second important parameter is the weight of the rig, which is mostly dictated by the type of tube material mounted on it. A bending fixture that will evaluate the fatigue strength of the available tubes is in the development.

\section{Acknowledgements}

The authors would like to express their sincere thanks to the Deep Exploration Technologies Cooperative Research Centre (DET CRC) for their financial supports towards this project.

\section{References}

[1] Jaworsk A, Coiled Tubing ... Operations and Services, Part 3 -Tube Technology and Capabilities, World Oil, Feb. 1992.

[2] Coil Tubing Manual, CTES, LP, http://www.ctes.com , 2005, accessed April 2012.

[3] Avakov, V., Foster, J., and Smith, E., Coiled Tubing Life Prediction, OTC 7325, 25th Annual OTC, Houston, May 1993.

[4] Jaworsky, A. and Williams, J, Development of Composite Coiled Tubing for Oilfield Services, Society of Petroleum Engineers, 1993.

[5] Fuller, O., Australian Researchers Record a World First with Successful Carbon Fiber HG Drill Rod Trial, Press Release, DET-CRC, March 2012.

[6] Preliminary samples of carbon fiber tubing are tested for drilling operation by DET CRC training facility at Brukunga, DET-CRC press release, 2012.

[7] Carbon Fibre Development and Design Process, http://www.teaklecomposites.com.au/development-design-process.html, 2008, accessed May 2012.

[8] Farag, M, Materials and Process Selection for Engineering Design, Taylor and Francis Group, Wiltshire, 2007.

[9] Ashby, M., Materials Selection Charts, in ASM Metals Handbook, Vol, 20 Dieter, G. Volume Chair. ASM International, Materials Park, OH, 1997a. pp. 266-280.

[10] Dargie, P., Parmeshwar, K., and Wilson W, MAPS 1: Computer aided design system for preliminary material and manufacturing process selection, Trans, ASME J. Mech. Design, 104, 126-136, 1982.

[11] MacMaster, F., Chan, K, Bergsma, S and Kassner, M, Aluminium Alloy 6069 part II: Fracture Toughness of 6061-T6 and 6069-T6, Material Science and Engineering, A289, pp. 54-59, 2000. 